\title{
GELADO COMESTÍVEL DE KEFIR ADICIONADO DE POLPA DE JABUTICABA E MORANGO
}

\author{
Kefir ice cream with jabuticaba and strawberry pulp
}

\author{
Lidia Betina Hendges Pletsch ${ }^{1}$ *, Joseana Severo ${ }^{1}$, Gislaine Hermanns ${ }^{1}$, \\ Leidi Daiana Preichardt ${ }^{1}$
}

\begin{abstract}
RESUMO
A crescente busca dos consumidores por alimentos diferenciados, que além de exercer suas funções básicas, apresentem também benefícios à saúde de quem os consome, tem proporcionado o desenvolvimento de novos produtos alimentícios. Dessa forma, buscou-se desenvolver um gelado comestível inovador, utilizando leite fermentado de kefir. Este foi adicionado de polpa de jabuticaba e morango e avaliado quanto à qualidade físico-química e microbiológica após 60 dias de armazenamento a temperatura de $-2{ }^{\circ} \mathrm{C}$. O gelado comestível apresentou significativos teores de compostos fenólicos e atividade antioxidante e, ainda, valores consideráveis de bactérias láticas $\left(1,0 \times 10^{8} \mathrm{UFC}^{-g^{-1}}\right)$ e bolores e leveduras $\left(7,6 \times 10^{7} \mathrm{UFC} \mathrm{g}^{-1}\right)$ durante o período de armazenamento. A análise sensorial do produto, realizada nos tempos 0,30 e 60 dias de armazenamento, demonstrou que o produto apresenta aceitabilidade superior a $80 \%$, nos atributos textura, odor, sabor e cor. Conclui-se que o produto pode ser uma alternativa promissora na oferta de alimentos com potencial funcional, apresentando qualidade sensorial e microbiológica durante os 60 dias de armazenamento.
\end{abstract}

Palavras-chave: inovação; bactérias láticas; alimentos funcionais; análise sensorial; atividade antioxidante.

\begin{abstract}
The growing consumer demand for differentiated foods, which in addition to performing their basic functions, also have health benefits to consumers, has led

1 Instituto Federal Farroupilha, Campus Santo Augusto. Rua Fábio João Adolhe, 1100, Floresta, 98590 000, Santo Augusto, RS, Brasil. E-mail: lidiabetina02@outlook.com

* Autor para correspondência
\end{abstract}

Recebido / Received: 09/10/2018

Aprovado / Approved: 19/02/2019 
to the development of new food products. Therefore, an innovative frozen product was developed using fermented kefir milk added with the pulp of jabuticaba and strawberry. Physicochemical and microbial analysis were performed after 60 days of storage at $-2{ }^{\circ} \mathrm{C}$. The elaborated frozen product showed significant levels of phenolic compounds and antioxidant activity, as well as significant values for lactic acid bacteria $\left(1.0 \times 10^{8} \mathrm{CFU}^{-1} \mathrm{~g}^{-1}\right)$ and molds and yeasts $\left(7.6 \times 10^{7} \mathrm{CFU} . \mathrm{g}^{-1}\right)$ during the storage period. The sensorial analysis of the product, performed at 0,30 and 60 days of storage, revealed acceptability of more than $80 \%$ in texture, odor, taste and color attributes. It is concluded that the product may be a promising alternative in the supply of foods with functional potential, maintaining sensorial and microbiological quality during the 60 days of storage.

Keywords: innovation; lactic acid bacteria; functional foods; sensory analysis; antioxidant activity.

\section{INTRODUÇÃO}

A indústria de gelados comestíveis tem se apresentado como um mercado promissor no setor alimentício, devido à variedade e aceitação desses produtos pelos consumidores. Os gelados comestíveis são produtos congelados obtidos a partir de uma emulsão de gorduras e proteínas; ou de uma mistura de água e açúcar(es). Podem ser adicionados de outro(s) ingrediente(s) desde que não descaracterize $(\mathrm{m})$ o produto (BRASIL, 2005), resultando em uma ampla gama de possibilidades para a indústria de alimentos.

A fermentação é um dos mais antigos métodos de conservação de alimentos, que além de aumentar a conservabilidade, proporciona aumento no valor nutricional do alimento (MARSH et al., 2014). Apesar do leite fermentado de kefir ainda não ser produzido em escala industrial no Brasil, esse produto é largamente produzido e consumido de forma artesanal, e estudos vêm demonstrando seu potencial para a indústria alimentícia (DINIZ et al., 2003; LEITE et al., 2013; ARAÚJO et al., 2017). De acordo com o Regulamento Técnico de Identidade e Qualidade de Leites Fermentados, o leite fermentado de kefir se caracteriza como o produto cuja fermentação se realiza com espécies dos gêneros Leuconostoc, Lactococcus e Acetobacter, com produção de ácido lático, etanol e dióxido de carbono (BRASIL, 2007). A fermentação do leite com o kefir resulta na formação de compostos que não estavam presentes inicialmente no leite, tais como peptídeos, vitaminas e um exopolissacarídeo específico do kefir, o kefiran, que aumenta a viscosidade e melhora as propriedades reológicas do leite fermentado. O kefiran também contribui com as propriedades antioxidantes, anticancerígenas e antimicrobianas do kefir (SHARIFI et al., 2017). Os ácidos orgânicos, diacetil, peróxido de hidrogênio e bacteriocinas, formados durante a fermentação, resultam no efeito de bioconservação do kefir (HANSEN, 2002; RIBEIRO et al., 2015).

Os grãos de kefir têm forma irregular, podendo ser brancos ou amarelos, de consistência elástica e com diâmetro muito variado (1 a $30 \mathrm{~mm}$ ), dependendo das condições de cultivo. Estes grãos podem conter uma microbiota variável e simbiótica constituída por leveduras fermentadoras de lactose (Kluyveromyces marxianus) e leveduras não fermentadoras de lactose (Saccharomyces omnisporus e Saccharomyces cerevisae e Saccharomyces exiguus), além 
das espécies de bactérias Lactobacillus casei, Bifidobacterium sp. e Streptococcus salivarus subsp. thermophilus. Sua composição microbiana é variável, podendo sofrer influência de região geográfica, do tempo de utilização, do substrato utilizado para fermentação dos grãos e das técnicas utilizadas para sua manipulação (WSZOLEK et al., 2001; MARSH et al., 2014; YILMAZERSAN et al., 2018).

O kefir pode ser considerado um probiótico formado por uma associação simbiótica composta por diversas leveduras e bactérias, capaz de melhorar o equilíbrio microbiano intestinal, produzindo efeitos benéficos à saúde, tais como redução dos efeitos de intolerância à lactose, proteção contra microrganismos patogênicos, modulação dos níveis de colesterol, atividade anticarcinogênica (DINIZ et al., 2003; HERTZLER; CLANCY, 2003; MARSH et al., 2014; HATMAL et al., 2018). Evidências indicam que o kefir está relacionado com a inibição da proliferação e indução da apoptose em células tumorais (SHARIFI et al., 2017).

O flavour do kefir é resultado da atividade metabólica simbiótica das várias espécies de bactérias e leveduras que se encontram naturalmente nos grãos, através da produção de diferentes ácidos orgânicos responsáveis pelo aroma e sabor desse produto (FARNWORTH, 2005; DERTLI; ÇON, 2017). A fermentação realizada por bactérias e leveduras confere à bebida características sensoriais singulares, e a incorporação de sucos de fruta e vegetais aos leites fermentados pode ser uma alternativa viável no aumento da aceitabilidade desse produto (MARSH et al., 2014; ARAÚJO et al., 2017).

As frutas e seus derivados possuem naturalmente compostos importantes para manutenção da saúde, como os compostos fenólicos, que possuem comprovada atividade antioxidante, antimicrobiana, antiinflamatória e vasodilatadora (AHERNE; O'BRIEN, 2002; CASSIDY, 2018). Frutas que apresentam a coloração variando do vermelho ao azul são importantes fontes de compostos fenólicos em dietas alimentares devido à presença das antocianinas, como é o caso do morango e da jabuticaba (OLIVEIRA et al., 2003; CASSIDY, 2018). As antocianinas são capazes de trazer benefícios à saúde de diversas maneiras, como por exemplo, capturando radicais livres e diminuindo lesões oxidativas que podem desencadear doenças crônicas degenerativas (AHERNE; O'BRIEN, 2002; LIMA et al., 2008). A jabuticaba, apesar de não ser ainda muito utilizada pela indústria alimentícia, tem demonstrado ser uma importante fonte de sais minerais, vitaminas, taninos, fenólicos e fibras (LIMA et al., 2008; LEITE-LEGATTI et al., 2012).

Dessa forma, o objetivo foi de elaborar um gelado comestível inovador, utilizando leite fermentado de kefir com a adição de polpa de jabuticaba e morango, e avaliálo quanto à qualidade físico-química, microbiológica e sensorial durante 60 dias de armazenamento.

\section{MATERIAIS E MÉTODOS}

\section{Produção do gelado comestível de kefir adicionado de polpa de jabuticaba e morango}

Grãos de kefir artesanal, doados por moradores da Região Celeiro do RS, foram utilizados para elaboração do leite fermentado de kefir. Inicialmente foi realizada a reativação dos grãos, já que estes se encontravam congelados. Para isso, os grãos foram incubados em frascos de $250 \mathrm{~mL}$ com leite UHT integral, em uma proporção 1:5 (grãos:leite) a $27^{\circ} \mathrm{C} \pm 2{ }^{\circ} \mathrm{C}$, durante 24 horas (h). A partir dos grãos de kefir reativados, estes separados do leite fermentado através da utilização de uma peneira de plástico, sendo o leite fermentado descartado, passouse a elaborar o leite fermentado utilizado na elaboração do gelado comestível de kefir. 
Para a obtenção do mesmo, uma mistura contendo 3\% dos grãos de kefir ativados, 3\% de iogurte natural integral, com o objetivo de incorporar maior cremosidade ao produto sem a utilização, por exemplo, de creme de leite, um ingrediente com índices elevados de gordura $(35 \%)$ sendo que o iogurte integral apresenta de 3 a 5,9\% de teor de gordura, constatando a mesma eficiência no atributo cremosidade em relação ao creme de leite. $\mathrm{O}$ iogurte integral apresenta bactérias láticas benéficas ao organismo na sua composição, incorporando ao gelado comestível este tipo de bactérias juntamente com àquelas que o leite fermentado de kefir já possui naturalmente, $10 \%$ de açúcar cristal e $84 \%$ de leite UHT integral foi incubada a $25{ }^{\circ} \mathrm{C} \pm 2{ }^{\circ} \mathrm{C}$ durante $24 \mathrm{~h}$. Foram realizados ensaios prévios para determinar o melhor tempo $\mathrm{x}$ temperatura para obtenção do leite fermentado. Após esse período, os grãos foram novamente separados, como já citado anteriormente na reativação dos grãos de kefir, descartando-se ainda o soro e obtendo-se uma concentração mais sólida de leite fermentado através de filtração utilizando um tecido de algodão esterilizado, ou seja, a parte sólida foi utilizada para a elaboração do gelado comestível, sem a presença de soro. $\mathrm{Na}$ Tabela 1 estão apresentados os ingredientes utilizados na elaboração do gelado comestível de kefir adicionado de polpa de jabuticaba e morango.

Tabela 1 - Ingredientes utilizados na elaboração do gelado comestível de kefir adicionado de polpa de jabuticaba e morango

\begin{tabular}{lc}
\hline Ingredientes & $\mathbf{\%}$ \\
\hline Leite fermentado & 57,0 \\
Leite condensado & 30,0 \\
Polpa de Jabuticaba & 6,0 \\
Polpa de Morango & 6,0 \\
Açúcar Cristal & 0,7 \\
Corante Vermelho (Arcolor & ) \\
\hline
\end{tabular}

Para elaboração do gelado comestível foi realizada a aeração do leite condensado e do leite fermentado à base de kefir durante 5 minutos, utilizando batedeira industrial $\left(\mathrm{MBBraesi}{ }^{\circledR}\right)$. Em seguida, foram adicionadas as polpas de jabuticaba e morango, e então realizada aeração por mais 10 minutos. $\mathrm{Na}$ sequência, foi incorporado à formulação, corante alimentício vermelho (Arcolor ${ }^{\circledR}$ ), e realizada a homogeneização mistura manual. $\mathrm{O}$ produto foi então congelado a $-4{ }^{\circ} \mathrm{C} \pm 2{ }^{\circ} \mathrm{C}$ por $10 \mathrm{~h}$. Passado esse período a mistura foi novamente aerada e congelada por mais $2 \mathrm{~h}$ à mesma temperatura de congelamento, com o objetivo de promover maior cremosidade ao produto, conforme apresentado no fluxograma da Figura 1.

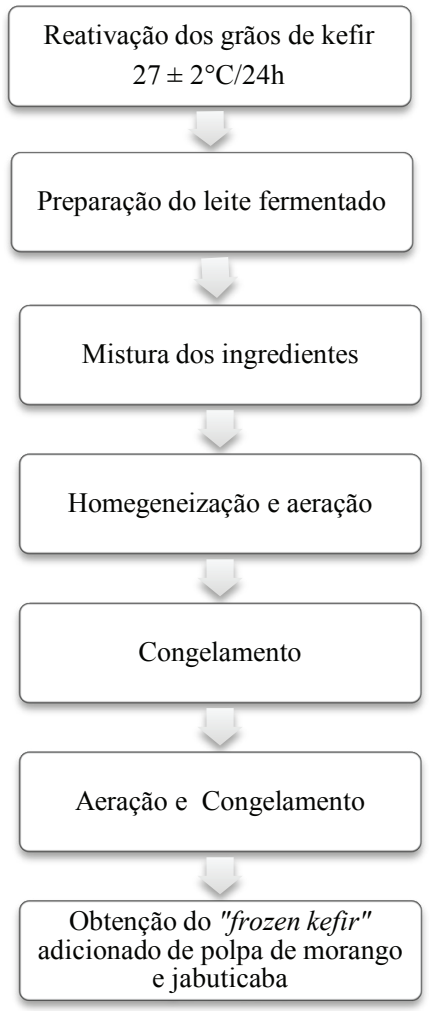

Figura 1 - Fluxograma de produção do gelado comestível de kefir adicionado de polpa de jabuticaba e morango 
Para elaboração das polpas de morango e jabuticaba foram utilizados frutos maduros, previamente higienizados, e despolpados em equipamento DES- $60^{\circledR}$ utilizando peneiras de $1,5 \mathrm{~mm}$. As polpas foram pasteurizadas a $75^{\circ} \mathrm{C}$ por 10 minutos e posteriormente congeladas até o momento de sua utilização.

\section{Análises físico-químicas e microbiológicas}

As análises realizadas para a caracterização do gelado comestível de kefir adicionado de polpa de jabuticaba e morango foram: proteína bruta pelo método de Kjeldahl com fator de correção de 6,38 utilizado para produtos lácteos, gordura pelo método Blighdyer, acidez titulável (AT), determinada por titulometria e expressa em \% ácido lático, umidade, cinzas, extrato seco total e extrato seco desengordurado, seguindo as Normas do Instituto Adolfo Lutz para derivados lácteos (IAL, 2008).

As antocianinas totais foram quantificadas pelo método de espectrofotometria descrito por Lees e Francis (1972), sendo os resultados expressos em mg EC3G.100g-1 (equivalente Cianidina3-glicosídeo por $100 \mathrm{~g}$ de amostra). Os compostos fenólicos totais também foram quantificados por espectrofotometria, utilizando o reagente de FolinCiocalteu $\left(\right.$ Sigma $\left.^{\circledR}\right)$, sendo os resultados expressos em mg EAG.100g ${ }^{-1}$ (equivalente ácido gálico por $100 \mathrm{~g}$ de amostra), a partir de curva padrão com ácido gálico (SINGLETON e ROSSI, 1965). A atividade antioxidante foi determinada com a utilização do radical ABTS (2,2'azino-bis-3-etilbenzotiazolin 6-ácido sulfônico) (Sigma ${ }^{\circledR}$ ), sendo os resultados expressos em $\mu \mathrm{g} \mathrm{TE} . \mathrm{g}^{-1}$ (equivalente Trolox por grama de amostra) utilizando curva padrão com Trolox (6-Hidroxi-2,5,7,8tetrametilchroman-2-ácido carboxílico) $\left(\right.$ Sigma $\left.^{\circledR}\right)$ de acordo com metodologia proposta por Re et al. (1999).

As polpas de jabuticaba e morango utilizadas para elaboração do gelado comestível também foram caracterizadas quanto aos teores de antocianinas totais, compostos fenólicos totais e atividade antioxidante, conforme metodologias descritas anteriormente. A acidez titulável (AT) das polpas foi quantificada por titulometria e os resultados expressos em \% de ácido cítrico, e sólidos solúveis (SS) quantificados utilizando refratômetro de mesa $\left(\right.$ Shimadzu $\left.^{\circledR}\right)$, com resultados expressos em ${ }^{\circ}$ Brix (IAL, 2008).

As análises microbiológicas foram realizadas segundo metodologias descritas em American Public Health Association (APHA, 2001). Para coliformes totais e termotolerantes, foi utilizada a técnica do Número Mais Provável (NMP.g-1). A contagem de bolores e leveduras (UFC. ${ }^{-1}$ ) foi realizada por plaqueamento em superfície em meio de ágar batata (Himedia ${ }^{\circledR}$ ) acidificado, com pH final 3,5 e incubado a $25{ }^{\circ} \mathrm{C}$, por 5 dias. Para a realização da análise de bactérias ácido-láticas procedeu-se plaqueamento em superfície, utilizando-se Ágar MRS (Lactobacillus MRS Ágar) (Himedia ${ }^{\circledR}$ ), com incubação sob anaerobiose a $36{ }^{\circ} \mathrm{C}$ por 48 72h (IDF, 1983).

Todas as análises foram realizadas em triplicata e as médias obtidas foram utilizadas para calcular o desvio padrão e submetidas ao teste de Tukey a 5\% de significância $\left(\mathrm{XLSTAT}^{\circledR}, 2016\right)$.

\section{Análise sensorial}

O projeto foi submetido e aprovado pelo Comitê de Ética em Pesquisa do Instituto Federal Farroupilha (Parecer CEP n ${ }^{\circ}$ 051499/2015, CAAE - 45796815.7.0000.5574) para a execução da avaliação sensorial.

A avaliação sensorial foi realizada por 40 provadores não treinados, de faixa etária entre 18 e 42 anos, sendo 26 do sexo feminino e 14 do sexo masculino. Foram avaliados os atributos de textura, odor, cor e sabor, utilizando escala hedônica de nove pontos para cada um dos atributos 
avaliados (1: gostei muitíssimo; 9: desgostei muitíssimo) avaliada no período de 0, 30 e 60 dias de armazenamento. Já a intenção de compra foi avaliada por meio de escala de cinco pontos (1: certamente compraria; 5: certamente não compraria). A amostra de gelado comestível de kefir foi apresentada em copos plásticos descartáveis de $80 \mathrm{~mL}$ com aproximadamente $25 \mathrm{~g}$ de amostra à temperatura de congelamento.

\section{RESULTADOS E DISCUSSÃO}

O consumo e a utilização de frutas vermelhas, como a jabuticaba e o morango, torna-se uma opção interessante para a indústria alimentícia, tendo em vista que, além de serem muito bem aceitas sensorialmente, essas frutas são reconhecidas fontes de compostos antioxidantes (LIMA et al., 2008; LEITE-LEGATTI et al., 2012; CASSIDY, 2018). Apesar de apresentar valores superiores de fenóis e antocianinas totais, quando comparada com a polpa de morango, a polpa de jabuticaba apresentou menor atividade antioxidante (Tabela 2). A atividade antioxidante de frutas e hortaliças tem sido atribuída à atividade de enzimas, como: superóxido desmutase, catalase e peroxidase, de compostos do metabolismo secundário: fenólicos (como ácidos fenólicos, flavonóis, antocianinas) e terpenoides (como carotenos e licopenos), e de vitaminas (como C, E e A). Além disso, sabe-se que frações individuais desses compostos podem apresentar atividade antioxidante diferente e que também essas frações podem atuar de forma sinérgica, ou seja, podem aumentar a atividade dos antioxidantes em combinações adequadas (KIRAKOSYAN et al., 2010). Dessa forma, frações e compostos não quantificados podem ser os responsáveis pela maior atividade antioxidante apresentada pela polpa de morango.

A jabuticaba e o morango possuem acidez característica, sendo os teores de sólidos solúveis (SS) e acidez total (AT) encontrados nas polpas (Tabela 2) similares ao verificado na literatura para frutos de jabuticaba e de acordo com a legislação para polpa de morango (LIMA et al., 2008; BRASIL, 2018a). Os resultados da caracterização físico-química do gelado comestível de kefir adicionado de polpa de jabuticaba e morango estão apresentados na Tabela 3.

Por ser um produto inovador, não foram encontrados trabalhos sobre gelados comestíveis elaborados com leite fermentado

Tabela 2 - Caracterização físico-química da polpa dos frutos de jabuticaba e morango utilizados na elaboração do gelado comestível de kefir adicionado de polpa de jabuticaba e morango

\section{Características}

SS $\left({ }^{\circ}\right.$ Brix $)$

AT (\% ác. cítrico)

Fenóis Totais (mg EAG $100 \mathrm{~g}^{-1}$ )

Antocianinas Totais (mg EC3G $100 \mathrm{~g}^{-1}$ )

Atividade Antioxidante ( $\mu \mathrm{g}$ Eq. Troloxg $\left.{ }^{-1}\right)$
Polpa de Jabuticaba Polpa de Morango

$$
\begin{array}{cc}
10,90 \pm 0,66^{\mathrm{a}} & 7,02 \pm 0,67^{\mathrm{b}} \\
0,91 \pm 0,17^{\mathrm{b}} & 0,98 \pm 0,03^{\mathrm{a}} \\
530,26 \pm 3,10^{\mathrm{a}} & 212,86 \pm 12,30^{\mathrm{b}} \\
185,52 \pm 1,45^{\mathrm{a}} & 59,25 \pm 1,45^{\mathrm{b}} \\
2,97 \pm 0,63^{\mathrm{b}} & 4,22 \pm 0,38^{\mathrm{a}}
\end{array}
$$

Médias \pm Desvio Padrão. Médias apresentadas com letras diferentes na mesma linha diferem significativamente pelo teste de Tukey a 5\%. SS: sólidos solúveis. AT: acidez titulável. EAG. $100 \mathrm{~g}^{-1}$ (equivalente ácido gálico por $100 \mathrm{~g}$ de amostra). EC3G.100g ${ }^{-1}$ (equivalente Cianidina3-glicosídeo por $100 \mathrm{~g}$ de amostra). Eq. Trolox.g-1 ${ }^{-1}$ (6Hidroxi-2,5,7,8-tetrametilchroman-2-ácido carboxílico por g de amostra). 
de kefir. Dessa forma, tendo em vista que o gelado comestível de kefir foi elaborado a partir de um leite fermentado, os resultados obtidos foram comparados ao frozen yogurt, que é um gelado comestível elaborado com yogurt. No entanto, a legislação brasileira não dispõe de padrões de identidade e qualidade para os gelados comestíveis de kefir e frozen yogurt. Nesse caso, adota-se a Resolução RDC n ${ }^{\circ} 266$, de 22 de setembro de 2005, da Agência Nacional de Vigilância Sanitária (ANVISA), que aprova o regulamento técnico para fixação de identidade e qualidade de gelados comestíveis, preparados, pós para o preparo e bases para gelados comestíveis (BRASIL, 2005).

Os teores de umidade e cinzas do gelado comestível de kefir foram de $71,11 \%$ e $0,83 \%$, respectivamente, valores próximos aos $73,81 \%$ e $0,79 \%$, relatado por Gonçalves e Eberle (2008) para frozen yogurt. Souza et al. (2017) também encontraram em frozen yogurt sabor tamarindo teores semelhantes ao desse estudo, relatando $69,76 \%$ de umidade e $0,79 \%$ de cinzas. Um valor elevado de extrato seco total é desejável, levando em consideração que derivados lácteos são alimentos ricos em sais minerais como cálcio, potássio, sódio, magnésio, entre outros componentes minerais, que influenciam diretamente nos teores de cinzas desses produtos.

O gelado comestível de kefir apresentou um teor significativo de proteína bruta na sua composição, de $5,10 \%$, superior ao encontrado por Gonçalves e Eberle (2008) para frozen yogurt, que foi de $2,43 \%$. O teor de gordura do mesmo foi de 13,07\%, similar ao encontrado por Gonçalves e Eberle (2008) em frozen yogurt (13,98\%). O teor de gordura do produto pode variar dependendo dos ingredientes adicionados na formulação, como o leite condensado, o iogurte e o leite integral.

A acidez obtida foi de $1,2 \%$ de ácido lático. Uma elevada acidez desse produto é esperada tendo em vista que o mesmo é preparado a partir do leite fermentado de kefir, no qual, através do processo fermentativo, a lactose é utilizada como fonte de energia pelos microrganismos com formação de

Tabela 3 - Caracterização físico-química do gelado comestível de kefir adicionado de polpa de jabuticaba e morango

\begin{tabular}{|c|c|}
\hline Características & Composição \\
\hline Umidade (\%) & $71,11 \pm 1,39$ \\
\hline Cinzas $(\%)$ & $0,83 \pm 0,03$ \\
\hline Proteínas (\%) & $5,10 \pm 0,55$ \\
\hline Gordura $(\%)$ & $13,07 \pm 1,59$ \\
\hline Extrato seco total $(\%)$ & $28,89 \pm 0,56$ \\
\hline Extrato seco desengordurado (\%) & $15,82 \pm 0,31$ \\
\hline AT (\% ác. lático) & $1,2 \pm 0,02$ \\
\hline Fenóis Totais (mg EAG $100 \mathrm{~g}^{-1}$ ) & $153,186 \pm 2,45$ \\
\hline Antocianinas Totais (mg EC3G $100 \mathrm{~g}^{-1}$ ) & $1,40 \pm 0,33$ \\
\hline Atividade antioxidante $\left( \pm \mathrm{g}\right.$ Eq. Trolox $\left.\mathrm{g}^{-1}\right)$ & $11,23 \pm 0,88$ \\
\hline
\end{tabular}

AT: acidez titulável. Médias \pm Desvio Padrão. EAG.100g-1 (equivalente ácido gálico por $100 \mathrm{~g}$ de amostra). EC3G.100g ${ }^{-1}$ (equivalente Cianidina3-glicosídeo por $100 \mathrm{~g}$ de amostra). Eq.Trolox.g ${ }^{-1}$ (Equivalente 6-Hidroxi2,5,7,8-tetrametilchroman-2-ácido carboxílico por $\mathrm{g}$ de amostra). 
ácido lático, conferindo acidez característica ao produto (SARKAR, 2008). A legislação brasileira estabelece uma acidez entre 0,5 e 1,5 g $100 \mathrm{~g}^{-1}$ ácido lático para o leite fermentado de kefir (BRASIL, 2007). Variações na composição e nos teores de acidez do leite fermentado podem estar relacionadas com as características dos microrganismos presentes no kefir, que podem variar entre diferentes regiões (WSZOLEK et al., 2001).

Apesar de um valor significativo de fenóis totais ter sido preservado no produto, 153,186 mg EAG. $100 \mathrm{~g}^{-1}$, o teor de antocianinas foi baixo, 1,40 mg EC3G.100 $\mathrm{g}^{-1}$, indicando possível degradação desses compostos. A degradação pode ter ocorrido devido à instabilidade das antocianinas ao oxigênio durante a aeração na preparação do gelado comestível de kefir.

A atividade antioxidante do produto apresentou valor de 11,23 $\mu \mathrm{g}$ EqTrolox. $\mathrm{g}^{-1}$, superior ao encontrado nas polpas de morango e jabuticaba. Esse resultado possivelmente está relacionado à presença de microrganismos como bactérias láticas e leveduras que produzem compostos com atividade antioxidante durante a fermentação (SAADI et al., 2017). Hatmal et al. (2018) observaram maior atividade antioxidante de leites fermentados a partir de leite de ovelha, quando comparados com o leite de vaca, sendo que o tempo de fermentação e o armazenamento também influenciaram na atividade antioxidante.

A contagem de coliformes totais e termotolerantes no gelado comestível de kefir demonstrou a ausência destes microrganismos, confirmando, dessa forma, a qualidade higiênico-sanitária do produto (Tabela 4). A ausência de coliformes termotolerantes pode indicar também que o processo de fermentação do kefir promoveu bioconservação e estabilização microbiológica no produto (WESCHENFELDER et al., 2009; RIBEIRO et al., 2015).

Segundo Sarkar (2008), a microbiota dos grãos de kefir é constituída de $10^{8}$ a $10^{9} \mathrm{UFC} \mathrm{g}^{-1}$ de bactérias ácido láticas, $10^{5}$ a $10^{6} \mathrm{UFC}^{-1} \mathrm{~g}^{-1}$ de bactérias ácido acéticas e $10^{5}$ a $10^{6}$ UFC. $^{-1}$ de leveduras. De acordo com a legislação brasileira, a contagem de microrganismos específicos presentes no kefir deverá ser no mínimo de $10^{7} \mathrm{UFC} \mathrm{g}^{-1}$ de bactérias ácido láticas e de $10^{4} \mathrm{UFCg}^{-1}$ para leveduras (BRASIL, 2007). A contagem obtida nessas análises é associada à presença natural destes microrganismos no produto, uma vez que os grãos de kefir são compostos por bactérias, principalmente láticas, em simbiose com as leveduras. $\mathrm{O}$ produto elaborado apresentou $1,0 \times 10^{8} \mathrm{UFC} \cdot \mathrm{g}^{-1} \mathrm{de}$ bactérias ácido láticas e 7,6 x 10 $0^{7} \mathrm{UFC} \mathrm{g}^{-1} \mathrm{de}$ leveduras, após 60 dias de armazenamento. Não houve desenvolvimento de bolores, indicando a boa higienização na produção. Gelados comestíveis são matrizes alimentares adequadas para a inclusão de microrganismos com potencial probiótico, não interferindo na qualidade global do produto (COSTA et al., 2015).

Tabela 4 - Resultados das variáveis microbiológicas analisadas do gelado comestível de kefir adicionado de polpa de jabuticaba e morango, armazenado pelo período de 60 dias.

\begin{tabular}{llc}
\cline { 2 - 2 } Variáveis microbiológicas & Resultados \\
\cline { 2 - 3 } & Bactérias ácido láticas $\left(\mathrm{UFC} \mathrm{g}^{-1}\right)$ & $1,0 \times 10^{8}$ \\
Leveduras $\left(\mathrm{UFC} \cdot \mathrm{g}^{-1}\right)$ & $7,6 \times 10^{7}$ \\
Coliformes totais e termotolerantes & N.D. \\
\hline
\end{tabular}

N.D. = Não Detectado $(<3,0 \mathrm{NMP} / \mathrm{g})$ 
Agência Nacional de Vigilância Sanitária determina que um produto probiótico, além de outros critérios, deve conter concentração mínima de células viáveis de $10^{8}$ a $10^{9} \mathrm{UFC}$ na recomendação diária do produto pronto para o consumo, comprovada até o final da validade do produto (BRASIL, 2018b). Desta forma, o gelado comestível de kefir demonstrou apresentar alta contagem de bactérias láticas e leveduras viáveis (Tabela 4), já que, se considerarmos a porção recomendada, de 120 g, para produtos similares a este, o número de bactérias lácticas e leveduras atingem valores de $10^{10}$ a $10^{9}$ UFC, respectivamente (BRASIL, 2003). Estudos avaliaram a composição química e microbiológica do kefir e identificaram 359 microrganismos em sua composição, entre eles Saccharomyces cerevisiae e Lactobacillus paracasei, sendo o Lactobacillus paracasei o mais abundante, o que comprova sua presença em derivados lácteos fermentados e sugerindo potencial probiótico a este alimento (MAGALHÃES et al., 2011). Assim, as contagens microbianas do gelado comestível de kefir obtidas neste estudo, associados a dados já publicados sobre microrganismos isolados de amostras de kefir (FARNWORTH, 2005; MAGALHÃES et al., 2011; DERTLI; ÇON, 2015), indicam um possível potencial probiótico para esse produto.

Através da análise sensorial percebe-se que os quatro requisitos avaliados, textura, odor, sabor e cor apresentaram boa aceitabilidade, superior a $80 \%$ durante todo o período avaliado (Figura 2). A textura apresentou um valor de $83 \%$ de aceitabilidade até o $30^{\circ}$ dia de armazenamento, surpreendendo com um aumento na sua aceitabilidade para $90 \%$ no $60^{\circ}$ dia de armazenamento. Os resultados obtidos no aspecto odor também foram positivos, não havendo variação significativa entre as análises realizadas durante todo o período de armazenamento.

No que diz respeito aos atributos sabor e cor, os provadores indicaram uma menor aceitabilidade do produto após 60 dias de armazenamento. Apesar do decréscimo observado para esses atributos no $60^{\circ}$ dia de armazenamento, o produto ainda apresenta boa aceitabilidade, superior a $80 \%$ para ambos os atributos. Alterações no sabor e na cor são decorrentes do processo natural de armazenamento de alimentos perecíveis, uma vez que o mesmo é um gelado comestível, no qual não houve adição de conservantes e/ou

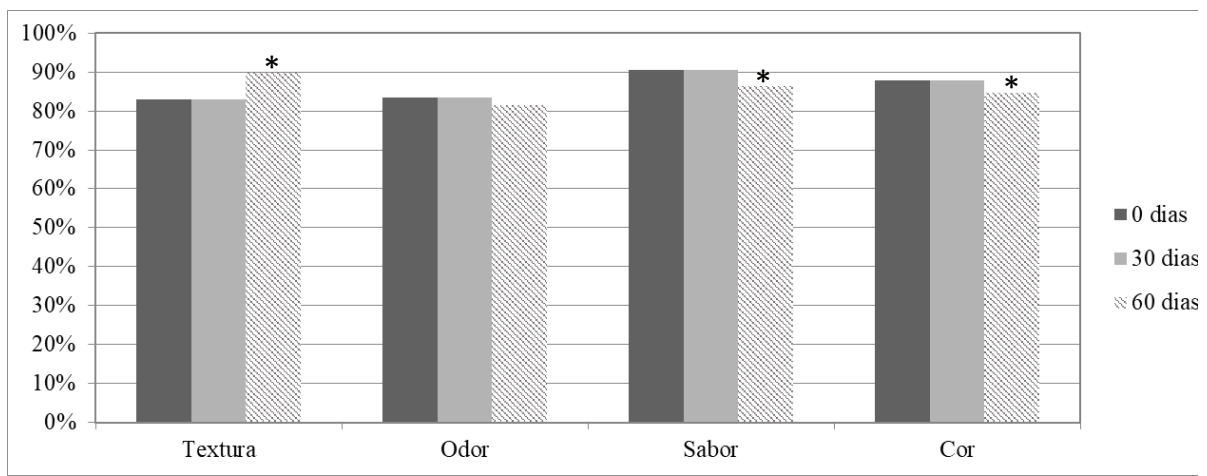

Figura 2 - Aceitabilidade do gelado comestível de kefir adicionado de polpa de jabuticaba e morango durante o período de 60 dias de armazenamento

* Indica diferença significativa em relação ao controle em cada período de armazenamento pelo teste de Tukey a 5\% de significância. 
outros aditivos químicos que poderiam auxiliar no aumento da sua conservação ao longo do armazenamento. Saadi et al. (2017), avaliando a composição dos principais ácidos orgânicos presentes no kefir (láctico, acético, propiônico e butírico) durante o armazenamento de diferentes amostras de kefir, verificaram a modificação nos teores desses compostos que estão intimamente relacionados com o sabor do kefir. Araújo et al. (2017) e Nogueira et al. (2016) relatam que a aceitabilidade do fermentado de kefir pode variar de acordo com a fruta e a concentração de polpa utilizada na saborização dos produtos. Quando avaliada a intenção de compra, o produto apresentou $82 \%$, confirmando o potencial mercadológico do gelado comestível de kefir adicionado de polpa de jabuticaba e morango.

Dessa forma, o gelado comestível elaborado com leite fermentado de kefir, apresenta resultados promissores, visando à incorporação de uma fruta nativa, a jabuticaba, assim como o leite fermentado de kefir no mercado lácteo brasileiro.

\section{CONCLUSÃO}

Conclui-se que a elaboração do gelado comestível de kefir adicionado de polpa de jabuticaba e morango manteve um teor significativo de antioxidantes e compostos fenólicos. A presença de bactérias láticas e leveduras no produto refletem a manutenção das características do leite fermentado de kefir, apesar do processamento e do armazenamento. Além disso, o produto apresentou boa aceitabilidade durante todo o período de armazenamento, diferindo entre os aspectos de textura, odor, sabor e cor apenas após 60 dias de armazenamento.

\section{REFERÊNCIAS}

AHERNE, S. A.; O'BRIEN, N. M. Dietery flavonols: chemistry, food content and metabolism. Nutrition, v. 18, n. 1, p. 75-81, 2002.

APHA, AMERICAN PUBLIC HEALTH ASSOCIATION. Microbiological Methods for Foods. Compendium of methods for the microbiological examination of foods, Washington. 4 ed., p. 676, 2001.

ARAÚJO, N. G. et al. Influência da concentração de polpa de goiaba na aceitação de fermentado de kefir. Revista do Instituto de Laticínios Cândido Tostes, v. 72, n. 4, p. 184-191, 2017.

BRASIL. Ministério da Agricultura, Pecuária e Abastecimento. Instrução Normativa $n^{\circ}$ 37 , de $1^{\circ}$ de outubro de 2018. Regulamento técnico para fixação dos padrões de identidade e qualidade para suco e polpa de frutas. Diário Oficial da República Federativa do Brasil, Brasília, 08 out. 2018a. Seção 1, p. 28.

BRASIL. Ministério da Agricultura, Pecuária e Abastecimento. Instrução Normativa $n^{\circ}$ 46 de 23 de outubro de 2007. Regulamento Técnico de Identidade e Qualidade de Leites Fermentados. Diário Oficial da República Federativa do Brasil, Brasília, 24 out. 2007. Seção 1, p. 4.

BRASIL. Ministério da Saúde. Agência Nacional de Vigilância Sanitária (ANVISA). Resolução RDC no 266, de 22 de setembro de 2005. Regulamento técnico para gelados comestíveis e preparados para gelados comestíveis. Diário Oficial da República Federativa do Brasil, Brasília, 23 set. 2005. Seção 1, p. 370.

BRASIL. Ministério da Saúde. Agência Nacional de Vigilância Sanitária (ANVISA). Resolução RDC no 359, de 23 de dezembro de 2003. Regulamento técnico de porções de alimentos embalados para fins de rotulagem 
nutricional. Diário Oficial da República Federativa do Brasil, Brasília, 26 dez. 2003. Seção 1, p. 28.

BRASIL. Ministério da Saúde. Agência Nacional de Vigilância Sanitária (ANVISA). Probióticos. Disponível em: http://portal.anvisa.gov.br/resultado-debusca?p_p_id $=101 \& p \_p \_l i f e c y c l e=0 \& p \_p$ state $=$ maximized $\& p \_p \_$mode $=v i e w \& p \_p \_$ col_id=column $1 \& p \_p \_c o l \_c o u n t=1 \& \_101$ struts_action $=\% 2$ Fasset_publisher $\% 2 \mathrm{Fview}$ content\&_101_assetEntryId $=2864062 \&$ 101 type $=$ content $\&$ 101_groupId $=219201 \& \_101$ urlTitle $=$ probioticos $\&$ inheritRedirect $=$ true Acesso em: 28 fev. 2018 b.

CASSIDY, A. Berry anthocyaninin take and cardiovascular health. Molecular Aspects of Medicine, v. 61, p. 76-82, 2018. DOI: 10.1016/j.mam.2017.05.002.

COSTA, R. G. B. et al. Sorvete. In: CRUZ, A. G.; ZACARCHENCO, P. B.; OLIVEIRA, C. A. F.; CORASSIN, C. H. (ed.) Processamento de Produtos Lácteos: Queijos, Leites Fermentados, Bebidas Lácteas, Sorvete, Manteiga, Creme de Leite, Doce de Leite, Soro em Pó e Lácteos Funcionais. Elsevier: Coleção Lácteos, 2015, v. 3, p. 138.

DERTLI, E.; ÇON, A. H. Microbial diversity of traditional kefir grains and their role on kefir aroma. LWT - Food Science and Technology, v. 85, p. 151-157, 2017.

DINIZ, R. O. et al. Atividade anti-inflamatória de kefir, um probiótico da medicina popular. Revista Brasileira de Farmacognosia, v. 13, p. 19-21, 2003.

FARNWORTH, E. R. Kefir - a complex probiotic. Food Science and Technology Bulletin Functional Foods, v. 2, n. 1, p. 1-17, 2005.
GONÇALVES, A. A.; EBERLE, I. R. Frozen Yogurt com Bactérias Probióticas. Alimentos e Nutrição - Brazilian Journal of Food and Nutrition, Araraquara, v. 19, n. 3, p. 291-297, 2008.

HANSEN, E. B. Commercial bacterial starter cultures for fermented foods of the future. International Journal of Food Microbiology, v. 78, p.119, 2002.

HATMAL, M. M. et al. Exploring the influence of culture conditions on kefir's anticancer properties. Journal of Dairy Science, v. 101, n. 5, p. 3771-3777, 2018.

HERTZLER, S. R.; CLANCY, S. M. Kefir improves lactose digestion and tolerance in adults with lactose maldigestion. Journal American Dietetic Association, v. 153, n. 5, p. $582-587,2003$.

IDF. International Dairy Federation. Yogurt: enumerations of characteristic microorganisms count technique at $37{ }^{\circ} \mathrm{C}$. Bulletin of International Dairy Federation, n. 117 , p. 1-4, 1983.

INSTITUTO ADOLFO LUTZ. Métodos físico-químicos para análise de alimentos, 4 ed., 1 ed. digital, 1020 p., São Paulo: Instituto Adolfo Lutz, 2008.

KIRAKOSYAN, A. et al. Interactions of antioxidants isolated from tart cherry (Prunuscerasus) fruits. Food Chemistry, v.122, p. 78-83, 2010.

LEES, D. H.; FRANCIS, F. J. Standardization of Pigment Analyses in Cranberries. HortScience, v. 7, p. 83-84, 1972.

LEITE, A. M. O. et al. Microbiological, technological and therapeutic properties of 
kefir: a natural probiótico beverage. Brazilian Journal of Microbiology, v. 44, n. 2, p. 341349, 2013.

LEITE-LEGATTI, A. V. L. et al. Jaboticaba peel: Antioxidant compounds, antiproliferative and antimutagenic activities. Food Research International, v. 49, p. 596-603, 2012.

LIMA, A. J. B. et al. Caracterização química do fruto jabuticaba (Myrciaria cauliflora Berg) e de suas frações. Archivos Latino americos de Nutrición, v. 58, n. 4, p. 416$421,2008$.

MAGALHÃES, K. T. et al. Brazilian kefir: structure, microbial communities and chemical composition. Brazilian Journal of Microbiology, São Paulo, v. 42, n. 2, p. 693-702, 2011.

MARSH, A. J. et al. Fermented beverages with health-promoting potential: Past and future perspectives. Trends in Food Science \& Technology, v. 38, p. 113-124, 2014.

NOGUEIRA, L. K. et al. Milk and açaí berry pulp improve sensorial acceptability of kefir fermented milk beverage. Acta Amazônica, v. 46, n. 4, p. 417-424, 2016.

OLIVEIRA, A. L. et al. Caracterização tecnológica de jabuticabas 'Sabara' provenientes de diferentes regiões de cultivo. Revista Brasileira de Fruticultura, v. 25, p. 397-400, 2003.

RE, R. et al. Antioxidant activity applyin gamin proved ABTS radical cation de colorization assay. Free Radical Biology and Medicine, v. 26, p. 1231-1237, 1999.

RIBEIRO, A. S. et al. Atividade antagonista de bactérias ácido-láticas isoladas de kefir artesanal frente a bactérias patogênicas.
Higiene Alimentar, v. 29, p. 2201, 2015.

SAADI, L. O. et al. Pulse ingredients supplementation affects kefir quality and antioxidant capacity during storage. LWT - Food Science and Technology, v. 86, p. 619-626, 2017.

SARKAR, S. Biotechnological innovations in Kefir production: a review. British Food Journal, v. 110, n. 3, p. 283-295, 2008.

SHARIFI, M. A. et al. Kefir: A powerful probiotics with anticancer properties. Medical Oncology, v. 34, p. 183-190, 2017.

SINGLETON, V. L.; ROSSI, J. A. J. R. Colorimetry of total phenolic with phosphomolybdic-phosphotungstic acid reagents. American Journal of Enology and Viticulture, v. 16, n. 3, p. 144-158, 1965.

SOUZA, R. L. A. et al. Elaboração e caracterização de frozen yogurt sabor tamarindo. Revista Brasileira de Agrotecnologia (Brasil) ISSN: 2317-3114, v. 7, n. 1, 2017.

WESCHENFELDER, S.; WIEST, J. M.; CARVAlHO, H. H. C. Atividade AntiEscherichia Coli em kefir e soro de kefir tradicionais. Revista Instituto Laticínios Cândido Tostes, Mar/Jun, n. 367/368, 64: 48-55, 2009.

WSZOLEK, M. et al. Properties of kefir made in Scotland and Poland using Bovine, Caprine and Ovine Milk with different Starter Cultures. LWT - Food Science and Technology, v. 34, p. 251-261, 2001.

YILMAZ-ERSAN, L. et al. Comparison of antioxidant capacity of cow and ewe milk kefirs. Journal of Dairy Science, v. 101, p. 3788-3798, 2018. 